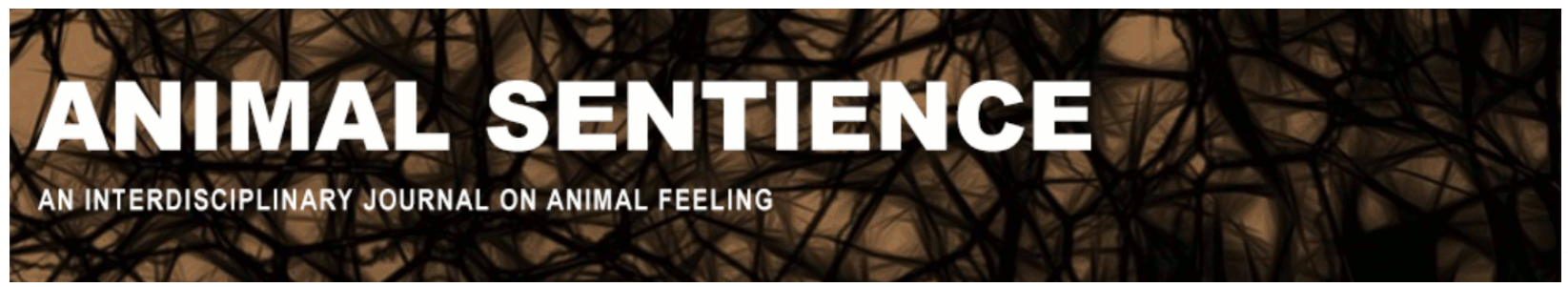

Droege, Paula (2017) We still need a theory. Animal Sentience 13(13)

DOI: $10.51291 / 2377-7478.1266$

Date of submission: $2017-11-26$

Date of acceptance: $2017-11-28$

(c) (i)

This article has appeared in the journal Animal

Sentience, a peer-reviewed journal on animal

cognition and feeling. It has been made open access,

free for all, by WellBeing International and deposited

in the WBI Studies Repository. For more information,

please contact

wbisr-info@wellbeingintl.org.

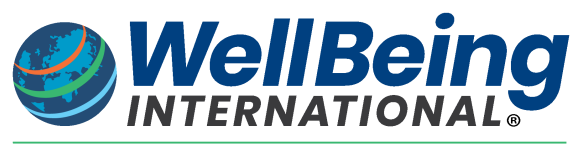

SOLUTIONS FOR PEOPLE, ANIMALS AND ENVIRONMENT 


\title{
We still need a theory
}

Commentary on Woodruff on Fish Feel

\author{
Paula Droege \\ Philosophy Department \\ Pennsylvania State University
}

\begin{abstract}
Woodruff (2017) has compiled a convincing array of data to support his contention that teleost fish feel pain. However, in the absence of an explanatory theory about the nature and function of consciousness, a checklist of criteria is insufficient to allay skeptical concerns. I offer a theory that can explain why features like selective attention and behavioral flexibility indicate consciousness. Consciousness represents the present moment in order to allow dynamic changes in actions or goals in response to situational demands.
\end{abstract}

Keywords: animal consciousness, temporal theory, flexibility

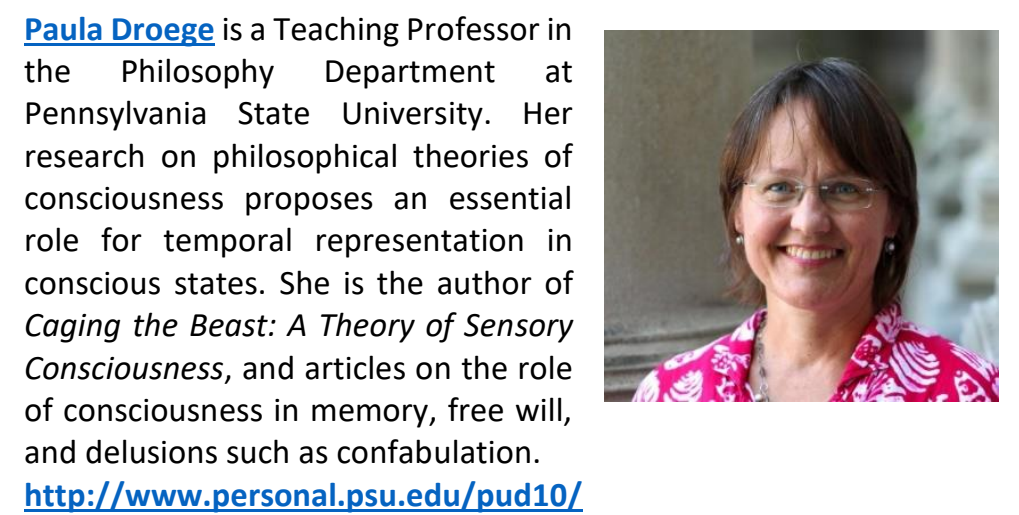

Woodruff (2017) has compiled a convincing array of data to support his contention that teleost fish feel pain. The anatomical structures that underlie consciousness include the optic tectum for selective attention and the integration of sensory information. The pallium is shown to support re-entrant processing, necessary for the coordination of multi-modal systems in order to respond flexibly to a dynamic environment. The columnar network of the pallium supports local recurrent connections involved in sensory binding. Systems that perform affective and motivational functions are demonstrated. Learning and memory also occur in teleost fish.

Who needs a theory? The primary reason I find all of this convincing is that it fits neatly into a theory of consciousness that explains why these structures are necessary. In my view, consciousness represents the present moment in order to facilitate flexible responses (Droege 2009, 2012). In a moment I will explain this view and how Woodruff's data fit it so well, but my main point is to emphasize the importance of philosophical theory in general.

In the absence of a theory about the nature and function of consciousness, there is always the possibility that the proposed structures could be in place and yet not be conscious. Skeptics can deny the 
ability of any objective evidence of consciousness (Nagel 1974). Or the particular structures may be considered insufficient in the absence of subjective report (Carruthers 2000). Or the homology between animal physiology and human physiology may be disputed (Key 2016; Rose et al. 2014).

Furthermore, there may be animals (or robots) capable of consciousness without the proposed structures. Perhaps selective attention and recurrent networks are not required for consciousness. Without a philosophical theory of consciousness, there is no way to address these concerns.

None of this is Woodruff's job. As a scientist, he has identified criteria that various consciousness researchers have proposed and provided evidence that teleost fish satisfy those criteria. It is the job of philosophers to provide better arguments that these criteria are indeed appropriate conditions for consciousness.

The function of consciousness is to track time. So, as a philosopher, let me do my part to place Woodruff's criteria into a frame of explanation. When we are conscious of something, we take it to be occurring now, in this moment. We do not consciously experience the past or future except in a special way that deserves separate treatment (Droege 2013). Consciousness in itself is not necessary for effective response, since unconscious habits guide so much of behavior. Consciousness is only necessary to be able to flexibly respond, that is, to respond differently to a situation in order to achieve a goal. Consciousness allows dynamic changes in action or goal in response to situational demands.

With just this tiny bit of theory, the structures Woodruff describes slot together to form a coherent picture of teleost consciousness. Selective attention is necessary to filter out sensory information that is irrelevant to the current goal. Consciousness is keeping track of how things are at the present moment so that behavior can be tuned to the task at hand while remaining alert to new opportunities and obstacles. Relevant sensory information is integrated temporally to assess the ongoing coordination of actions and events. Reentrant processing and recurrent networks are important to binding discretely processed sensations into objects and binding temporally asynchronous signals into a conscious representation of the present moment. Affective and motivational systems contribute to the feeling of consciousness. Without pleasure and pain, desire and aversion, there would be no reason to pursue one goal rather than another, no reason to learn or remember associations. Arguably non-conscious animals utilize similar systems to respond to stimuli, so they are not sufficient evidence of consciousness in themselves. Nonetheless, they are necessary to consciousness and so are among the criteria to be evaluated.

This last point raises another issue to keep in mind when assessing animal consciousness. Even with an explanatory theory in place, there is reason to be cautious about specifying necessary and sufficient conditions. I have given reasons to think several conditions are necessary to consciousness. Much more argument would be needed to determine whether they are jointly sufficient in every case and whether there might be a case where a condition is missing. Rather than pursue this ideal of logical completeness in a philosophical vacuum, I recommend a more pragmatic approach. Philosophical theories about the nature and function of consciousness should be sensitive to empirical evidence from neuroscience and comparative ethology. In turn, empirical evidence should be evaluated in light of the best philosophical theories of consciousness. This joint method of problem-solving is the only way to move forward on both the conceptual and empirical questions raised by consciousness in fish and other animals. 


\section{References}

Carruthers, P. (2000) Phenomenal Consciousness: A Naturalistic Theory. Cambridge: Cambridge University Press.

Droege, P. (2009) Now or Never: How Consciousness Represents Time. Consciousness and Cognition 18(1): 78-90.

- - - (2012) Assessing Evidence for Animal Consciousness: The Question of Episodic Memory. In Experiencing Animal Minds: An Anthology of Animal-Human Encounters, J. A. Smith \& R. W. Mitchell (Eds.), 231-45. Columbia University Press.

- - (2013) Memory and Consciousness. Philosophia Scientiae 17(2): 171-93.

Key, B. (2016) Why fish do not feel pain. Animal Sentience 3(1).

Nagel, T. (1974) What Is It like to Be a Bat? Philosophical Review 83(4): 435-50.

Rose, J. D., Arlinghaus, R., Cooke, S. J., Diggles, B. K., Sawynok, W., Stevens, E. D., \& Wynne, C. D. L. (2014) Can Fish Really Feel Pain? Fish and Fisheries 15(1):97-133.

Woodruff, M. (2017) Consciousness in teleosts: There is something it feels like to be a fish. Animal Sentience 13(1). 